\title{
Impact of potassium and phosphorus in biomass on the properties of fast pyrolysis bio-oil
}

\author{
Scott W. Banksł, Daniel J. Nowakowskit*, Anthony V. Bridgwater \\ Aston University, European Bioenergy Research Institute, Bioenergy Research Group, \\ Birmingham B4 7ET, United Kingdom
}

\section{KEYWORDS}

Beech wood; potassium impregnation; phosphorous impregnation; fast pyrolysis; bio-oil quality; bio-oil stability.

\section{ABSTRACT}

This study investigates fast pyrolysis bio-oils produced from alkali metal impregnated biomass (beech wood). The impregnation aim is to study the catalytic cracking of the pyrolysis vapours due to potassium or phosphorous. It is recognised that potassium and phosphorous in biomass can have a major impact on the thermal conversion processes. When biomass is pyrolysed in the presence of alkali metal cations, catalytic cracking of the pyrolysis liquids occurs in the vapour phase reducing the organic liquids produced and increasing yields of water, char and gas, resulting in a bio-oil which has a lower calorific value and an increased chance of phase separation. Beech wood was impregnated with potassium or phosphorus (K-impregnation and $\mathrm{P}$-impregnation 
respectively) in the range of $0.10-2.00$ wt. \%. Analytical pyrolysis-gas chromatography-mass spectrometry (Py-GC-MS) was used to examine the pyrolysis products during thermal degradation, and thermogravimetric analysis (TGA) to examine the distribution of char and volatiles. Both potassium and phosphorus are seen to catalyse the pyrolytic decomposition of biomass and modify the yields of products. 3-furaldehyde and levoglucosenone become more dominant products upon P-impregnation pointing to rearrangement and dehydration routes during the pyrolysis process. Potassium has a significant influence on cellulose and hemicellulose decomposition, not just on the formation of levoglucosan, but also other species like 2(5H)furanone or hydroxymethyl-cyclopentene derivatives. Fast pyrolysis processing has also been undertaken using a laboratory scale continuously fed bubbling fluidised bed reactor with a nominal capacity of $1 \mathrm{~kg} \mathrm{~h}^{-1}$ at the reaction temperature of $525^{\circ} \mathrm{C}$. An increase in the bio-oil's viscosity during the stability assessment tests was observed with increasing percentage of impregnation for both additives. This is because bio-oil undergoes polymerisation while placed in storage due to the inorganic content. The majority of inorganics are concentrated in the char, but small amounts are entrained in the pyrolysis vapours and therefore end up in the bio-oil.

\section{INTRODUCTION}

Biomass is well recognised as a potential renewable energy source when considering a reduction in environmental concerns from fossil fuels. The main alternatives for thermal utilisation of biomass are pyrolysis, gasification and combustion. Fast pyrolysis converts biomass by rapid heating in the absence of oxygen and then rapid cooling of the vapours [1]. The products are biooil, char and non-condensable gases. During fast pyrolysis certain constituents within biomass 
(inorganic content i.e. ash) have negative effects on fast pyrolysis product yields and quality as defined by composition and long-term stability.

Biomass ash contains alkali metals which are known to catalyse cracking reactions of fast pyrolysis vapours and have a significant effect on fast pyrolysis product distribution including chemical composition of bio-oil [2-14]. Research by Sekiguchi and Shafizadeh [4] showed that inorganic compounds found naturally within biomass promote the formation of char and gas at the expense of pyrolysis liquid yield. An increase in char and gas yield at the expense of bio-oil due to the presence of ash during pyrolysis was observed in a number of studies for rice hull [5], sunflower stem [6] and miscanthus [7]. Thermogravimetric analysis (TGA) has been used extensively to study the effect of inorganic material on biomass pyrolysis. Studies by Nowakowski et al. $[8,15]$ found that pyrolysis product yields were adversely influenced by the presence of potassium. Potassium catalysed the pyrolysis products increasing the char yield from $6.7 \mathrm{wt} . \%$ for $\mathrm{HCl}$ treated willow to $19.8 \mathrm{wt}$ \% \% for K-impregnated willow samples. Also the potassium lowered the average first order activation energy for pyrolysis by up to $50 \mathrm{~kJ} \mathrm{mol.}{ }^{-1}$. Ebringerova et al. [16] showed that the first step in the formation of volatile compounds during pyrolysis of cellulose was through the compound levoglucosan. It was shown that high concentrations of levoglucosan were found in all high quality bio-oils. The presence of this compound can help to identify the quality of bio-oil and if any unwanted side reactions have occurred. Evans et al. [9] showed that the presence of potassium in biomass promotes the decomposition of levoglucosan, as well as other anhydrosugars, and also leads to the decomposition of cellulose to other unwanted products such as acetic acid and propanoic acid. This shows that higher concentrations of potassium in biomass lead to a lower quality bio-oil as the content of levoglucosan has been reduced and increased level of acidic products are formed. 
He et al. [17] found that the solid content in bio-oil includes small char particles entrained with vapours and collected in the liquid products in the condensation process. Bio-oil is preferred with minimal solid content to minimise instability and improve handling and upgrading. The study varied pyrolysis temperatures and feedstock moisture content, and found the solid content of biooil ranged between $1.23 \%$ and $2.86 \%$. From the results it was clear that the lower moisture content of the feedstock gave the lowest percentage of solid content in bio-oil, but there was no trend with the effect of pyrolysis temperatures on solid content. A low bio-oil solid content is desired as it has a direct effect on bio-oil stability due to catalysing reactions which take place within bio-oil whilst in storage. Bio-oil is chemically and thermally unstable due to its high content of reactive oxygen containing compounds. The instability of bio-oil can be observed by an increase in viscosity and water content over time which is known as aging which can be catalysed by bio-oil inorganic content $[12,13,18,19]$. The change in viscosity is greater than that in water content. During bio-oil storage the chemical composition changes towards thermodynamic equilibrium which results in changes to the viscosity, molecular weight and co-solubility [12, 13]. Bio-oil should be single phase, but during storage or thermal treatment the bio-oil can separate into two phases. Chemical reactions taking place during bio-oil aging change the polarity of the bio-oil components [18]. Certain reactions taking place produce water and compounds which are relatively nonpolar, therefore the overall water content is increased and the overall polarity of the organic content is decreased. This leads to an increased potential of phase separation occurring with the aged bio-oil. Aging of bio-oil leads to formation of larger molecules i.e. an increase in molecular weight [20], which also increases the potential of phase separation as the compounds decrease in solubility. The bio-oil can phase separate into a low viscosity aqueous phase and a high viscosity organic phase $[18,19,21]$. 
Many reactions may occur as bio-oil is a mixture of over 400 organic compounds. Diebold [18] reviewed several general chemical reactions which are thought to take place during bio-oil aging. Some of these reactions require a catalyst to take place, so depending on the amount of char (in particular the inorganic content) in the bio-oil can have a direct effect on the aging progress.

Special care has to be taken in handling, transportation, storage and bio-oil use due to its instability. There is no standard method for measuring stability of bio-oils but a simple test can be used to compare bio-oil sample stability. To compare the stability of different fast pyrolysis biooils a simple test has been developed $[12,22,23]$. In the test, $45 \mathrm{ml}$ of bio-oil in a $50 \mathrm{ml}$ bottle is kept at $80^{\circ} \mathrm{C}$ for 24 hours as this is claimed to simulate one year storage at ambient temperature. The change in viscosity and water content is measured so that the stability of bio-oil can be determined.

The objectives of this study were to explore the impact of specific ash components on fast pyrolysis liquid product yields and bio-oil quality. Two ash components are studied; potassium and phosphorus. Beech wood was impregnated with different concentrations of potassium and phosphorus separately $(0.10,0.50,1.00$ and $2.00 \mathrm{wt}$. \%) to identify the effect on bio-oil yields and quality (defined by composition and long-term stability).

\section{EXPERIMENTAL}

Feedstock. The biomass sample of beech wood (Fagus sylvatica) was purchased from J. Rettenmaier \& Söhne GmbH + Co. KG D-73494 Rosenberg (Germany).

Sample preparation. The beech wood samples were prepared before each set of impregnation experiments by grinding (Retsch Ltd., Germany, Heavy-Duty Cutting Mill, Type SM2000) and sieving to a particle size fraction of $0.25-1.00 \mathrm{~mm}$. After each impregnation the following particle size fractions were prepared for analysis: particle size $0.25-1.00 \mathrm{~mm}$ for fast pyrolysis processing 
and particle size $0.15-0.25 \mathrm{~mm}$ for thermogravimetric analysis (TGA) and pyrolysis - gas chromatography - mass spectrometry (Py-GC-MS) analysis. A biomass splitter (Sepor Ltd., Sepor micro riffle splitter, Jones type, Model: 040G-000) was used to obtain a representative sample for TGA and Py-GC-MS analyses.

Impregnation. A batch of $1 \mathrm{~kg}$ of beech wood was impregnated either with potassium in the form of potassium acetate or phosphorus in the form of phosphoric acid to achieve concentrations of $0.10,0.50,1.00$ and 2.00 wt. $\%$ of elemental potassium and phosphorus. The specific amounts of either potassium acetate or phosphoric acid to achieve the concentrations were diluted in 5 litres of deionised water then hand mixed with $1 \mathrm{~kg}$ of beech wood for 20 minutes. The biomass was left for 72 hours to ensure that the entire solution was absorbed. After the 72 hours the biomass was dried at $60^{\circ} \mathrm{C}$ for a further 48 hours.

ASTM ash content analysis. The ash content of the biomass and fast pyrolysis char samples was calculated using E 1755 ASTM method [24]. Prior to analysis all samples were dried at $60^{\circ} \mathrm{C} \pm$ $2^{\circ} \mathrm{C}$ for 24 hours instead of $105^{\circ} \mathrm{C}$ to ensure no light volatiles were released. Approximately 0.5 to $1.0 \mathrm{~g}$ of dried sample was ashed using a Carbolite AAF1 100 furnace heated to $250^{\circ} \mathrm{C}$ at $10^{\circ} \mathrm{C} \mathrm{min}$.' ${ }^{1}$ and held for 30 minutes, then increased to $575^{\circ} \mathrm{C}$ for 3 hours. Samples were then removed from the furnace to cool and be weighed. Samples were then replaced in furnace and heated to $575^{\circ} \mathrm{C}$ for 1 hour periods until sample weight was constant to within $0.3 \mathrm{mg}$. The reported data for ash were the average of three measurements.

Elemental analysis and heating values. A Carlo-Erba 1108 elemental analyser EA1108 was used to determine the elemental analysis for carbon, hydrogen and nitrogen. Carbon, hydrogen and nitrogen content (wt. \% on dry basis) were analysed in duplicate and average values were taken. 
The higher heating value (HHV) was calculated using Equation 1 [25] and the lower heating value (LHV) was calculated using Equation 2 [26]:

$$
\begin{aligned}
& \mathrm{HHV}_{\text {Dry }}=3.55 \mathrm{C}^{2}-232 \mathrm{C}-2230 \mathrm{H}+51.2 \mathrm{CH}+131 \mathrm{~N}+20600 \\
& \mathrm{LHV}_{\text {Dry }}=\mathrm{HHV}_{\text {Dry }}-2.442 *(8.936 \mathrm{H} / 100)
\end{aligned}
$$

Potassium and phosphorus content analysis. A PerkinElmer Optima 7300 DV Induced Coupled Plasma (ICP) emission spectrometer was used to determine the potassium and phosphorous content on impregnated beech wood. Prior to analysis the impregnated biomass was dried at $80^{\circ} \mathrm{C}$ for 4 hours, $0.25 \mathrm{~g}$ was then digested in $5 \mathrm{~cm}^{3} 30 \%$ nitric acid and mixed for 2 hours at ambient temperature, then heated for 12 hours at $80^{\circ} \mathrm{C} \pm 2^{\circ} \mathrm{C}$. After the 12 hours $5 \mathrm{~cm}^{3}$ of $25 \%$ hydrochloric acid was added and then heated for a further 4 hours at $80^{\circ} \mathrm{C} \pm 2^{\circ} \mathrm{C}$. The sample was then cooled and analysed by ICP emission spectrometer.

Thermogravimetric analysis (TGA). A PerkinElmer Pyris 1 thermogravimetric analyser was used to perform thermogravimetric analysis of untreated and impregnated beech wood samples. Dynamic heating of a $5 \mathrm{mg}$ sample from ambient temperature to $550^{\circ} \mathrm{C}$ with a heating rate of $20^{\circ} \mathrm{C}$ min. ${ }^{-1}$ in a nitrogen purge rate of $30 \mathrm{ml} \mathrm{min.} .^{-1}[27]$ was used to study pyrolysis. All analyses were performed in triplicate.

Pyrolysis-gas chromatography-mass spectrometry (Py-GC-MS). Untreated and impregnated beech wood samples $(3 \mathrm{mg}$ ) were pyrolysed using a CDS 5200 pyrolyser close-coupled to a PerkinElmer Clarus 680 gas chromatograph(GC) and Clarus 600S mass spectrometer (MS), to a pyrolysis temperature of $550^{\circ} \mathrm{C}$ (held for $15.0 \mathrm{~s}$ at $550^{\circ} \mathrm{C}$ ) at a heating rate of $20^{\circ} \mathrm{C} \mathrm{ms} .^{-1}$. The separation was carried out using a PerkinElmer Elite-1701 column (cross-bond: 14\% cyanopropylphenyl and $85 \%$ dimethyl polysiloxane; $30 \mathrm{~m}, 0.25 \mathrm{~mm}$ i.d., $0.25 \mathrm{~mm} \mathrm{df}$ ). The GC oven was held at $45^{\circ} \mathrm{C}$ for 5 minutes, then heated at $5^{\circ} \mathrm{C} \mathrm{min.}{ }^{-1}$ to $250^{\circ} \mathrm{C}$ and held at this temperature 
for 5 minutes. Proposed assignments $(\mathrm{m} / \mathrm{z}=45-300)$ were made from mass spectra detection using the NIST05 MS library and from assignments in the literature [28, 29].

Fast pyrolysis processing. The fast pyrolysis experiments were carried out in a $1 \mathrm{~kg} \mathrm{~h}^{-1}$ continuous bubbling fluidised bed reactor (\#4) shown in Figure 1 [30].

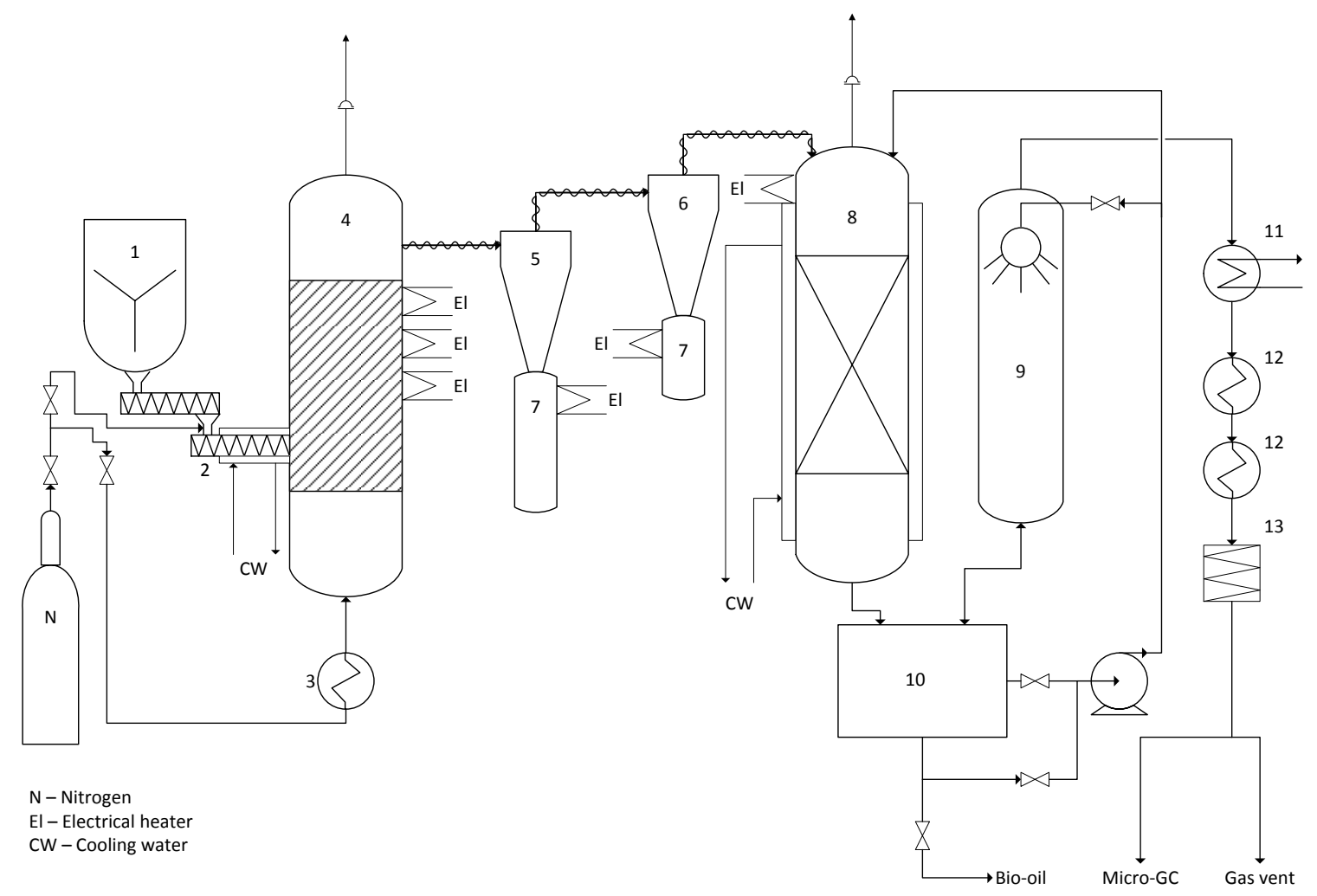

Figure 1. $1 \mathrm{~kg} \mathrm{h.-1} \mathrm{fast} \mathrm{pyrolysis} \mathrm{rig} \mathrm{set-up}$

1 - feed hopper, 2 - fast screw, 3 - nitrogen preheater, 4 - bubbling fluidised bed reactor, 5 cyclone one for larger particles, 6 - cyclone two for char fines, 7 - char pot, 8 - quench column, 9 - electrostatic precipitator, 10 - collection tank, 11 - water cooled condenser, 12 - dry ice / acetone condenser, 13 - cotton wool filter 
Biomass was continuously fed by speed regulated twin metering screws to a single fast screw (\#2) into $1 \mathrm{~kg} \mathrm{~h}^{-1}$ bubbling fluidised bed reactor. $1 \mathrm{~kg}$ of sieved quartz sand was used as bed material with a sand particle size range between 600 and $710 \mu \mathrm{m}$. The reactor was fluidised using preheated nitrogen on a single pass basis. The fast pyrolysis processing parameters can be found in Table 1. 
Table 1. Fast pyrolysis processing parameters

\begin{tabular}{|c|c|c|c|c|c|c|c|c|c|}
\hline \multirow{2}{*}{ Parameter } & \multicolumn{9}{|c|}{ Potassium and phosphorus impregnation } \\
\hline & Beech wood & $0.10 \mathrm{~K}$ & $0.50 \mathrm{~K}$ & $1.00 \mathrm{~K}$ & $2.00 \mathrm{~K}$ & $0.10 \mathrm{P}$ & $0.50 \mathrm{P}$ & $1.00 \mathrm{P}$ & $2.00 \mathrm{P}$ \\
\hline Pyrolysis temperature $\left({ }^{\circ} \mathrm{C}\right)$ & 525 & 525 & 525 & 530 & 525 & 525 & 525 & 540 & 525 \\
\hline Run time (min) & 110 & 80 & 80 & 95 & 75 & 85 & 50 & 105 & 50 \\
\hline Biomass moisture content & 9.63 & 1.79 & 2.63 & 2.03 & 2.78 & 1.09 & 2.61 & 2.67 & 2.57 \\
\hline Biomass used $^{\text {w.b. }}(\mathrm{g})$ & 1064.41 & 672.54 & 747.42 & 618.53 & 631.96 & 675.89 & 279.20 & 517.36 & 216.85 \\
\hline Hot vapour residence time & $<1.5$ & $<1.5$ & $<1.5$ & $<1.5$ & $<1.5$ & $<1.5$ & $<1.5$ & $<1.5$ & $<1.5$ \\
\hline
\end{tabular}

- wet basis 
All experiments were carried out with the aim of achieving an average pyrolysis bed temperature of $525 \pm 5^{\circ} \mathrm{C}$. The maximum deviation was always less than $5{ }^{\circ} \mathrm{C}$. Two heated cyclones in series (\#5 and \#6) separate char from the vapour and gas stream leaving the reactor. A quench column (\#8), cooled by a chilled water cooling jacket at $15^{\circ} \mathrm{C}$, was used to condense the vapours by directly contacting with ISOPAR ${ }^{\mathrm{TM}}$ (Isopar V. CAS number: 64742-46-7. Supplier: Multisol Limited) as the quench media controlled to between 20 and $25^{\circ} \mathrm{C}$. Aerosols were separated using a wet walled electrostatic precipitator (ESP, \#9) flushed with ISOPAR ${ }^{\mathrm{TM}}$. The main condensate, bio-oil, from the quench column and the wet ESP was collected in a common collection tank (\#10). ISOPAR ${ }^{\mathrm{TM}}$ was recycled to the quench column and ESP by skimming from the top of the collection tank. The remaining condensable light volatiles and vapours are condensed by a water cooled condenser $(\# 11)$ at $10-15{ }^{\circ} \mathrm{C}$, two dry ice - acetone condensers (\#12) in series at $-70{ }^{\circ} \mathrm{C}$ and finally a cotton wool filter (\#13) to minimise carry over. The non-condensable gases then pass through a diaphragm gas meter (to measure volume of gas) and an on-line Varian CP 4900 Micro-GC microgas chromatograph with a thermal conductivity detector (TCD) and two columns (Varian CP-5A molsieve and CP-PortaPLOT). Nitrogen, hydrogen, $\mathrm{CO}, \mathrm{CO}_{2}$ and hydrocarbons up to $\mathrm{C} 4$ are analysed by the micro-GC. Experimental temperatures were measured with K-type thermocouples and recorded using a Microlink 751 ADC unit using Windmill data logging software. Mass balances (wt. \% on dry basis) were calculated based on mass of biomass processed and final fast pyrolysis products of bio-oil, char and non-condensable gases. Previous work on the same experimental equipment had shown that fast pyrolysis experiments would produce reproducible results; therefore only one experiment was performed for each feedstock [31].

Dynamic viscosity. To determine the dynamic viscosity of bio-oil samples a Brookfield Viscometer model DV-II + pro rotational viscometer (accuracy, $\pm 1 \%$ full-scale range; 
repeatability, $0.2 \%$ full-scale range) was used. The viscometer was calibrated prior to analyse with a $4.7 \mathrm{cP}$ Brookfield silicone viscosity calibration standard. A temperature controlled water bath was used to maintain the bio-oil sample at $40 \pm 0.1^{\circ} \mathrm{C}$.

Water content. Volumetric Karl-Fischer (KF) titration was used to determine the water content of all fast pyrolysis liquid products, using a Mettler Toledo V20 KF titrator with Hydranal (R) K as a working medium and Hydranal (R) Composite $5 \mathrm{~K}$ as a titrant. The $\mathrm{KF}$ instrument was calibrated with HPLC-grade water prior to analysis and the system was flushed with the working medium between different samples. The water content was automatically calculated by the KF based on the weight of bio-oil sample used and reported visually. All analyses were performed in triplicate. The water content of the bio-oil was measured at three separate points $(33,50$ and $67 \%$ from the top of sample) to determine if the sample was single phase or separated. The bio-oil is classed as separated if the difference between two consecutive points is greater than $1 \mathrm{wt} . \%$ [32]. pH analysis. The acidity of the bio-oil samples was measured using a Sartorius PB-11 pH meter. Prior to each measurement the $\mathrm{pH}$ meter was calibrated with $\mathrm{pH}$ buffers $(\mathrm{pH}=2,4,7$ and 10) which were provided by Sartorius. To ensure exact readings were recorded the probe was cleaned between sample analyses to guarantee no cross contamination occurred. All analyses were performed in triplicate.

Bio-oil accelerated storage experiment. All bio-oil samples were centrifuged (60 minutes at $4200 \mathrm{rpm}$ ) to remove all ISOPAR ${ }^{\mathrm{TM}}$ prior to accelerated storage tests. Three $75 \mathrm{ml}$ samples of each bio-oil were placed and sealed in $100 \mathrm{ml}$ glass bottles which had been dried at $105^{\circ} \mathrm{C}$ for 4 hours to remove all moisture. All samples were placed in an oven at $80^{\circ} \mathrm{C}$ for 24 hours, as this is claimed to simulate one year degradation at ambient temperature [22]. To ensure no volatiles are released, the bottle lids were re-tightened after 10 minutes. After 24 hours the bio-oil was removed from the 
oven and left to cool to ambient temperature. The viscosity and water content were re-measured so a viscosity and water content index could be calculated (Equation 3 and Equation 4). An index of 1.00 indicates a perfectly stable liquid in which the viscosity or water content does not change with heating or time. Most applications for bio-oil require the bio-oil to retain its initial physical properties during storage, transport and use.

Viscosity index $\left(v_{\mathrm{I}}\right)$ :

$v_{I}=1+\frac{v_{1}-v_{0}}{v_{0}}$

$v_{0}-$ viscosity before the accelerated storage experiment $(0 \mathrm{~h})$

$v_{1}$ - viscosity after the accelerated storage experiment $(24 \mathrm{~h})$

Water content index $\left(w_{\mathrm{I}}\right)$ :

$w_{I}=1+\frac{w_{1}-w_{0}}{w_{0}}$

$w_{0}-$ water content before the accelerated storage experiment $(0 \mathrm{~h})$

$w_{1}-$ water content after the accelerated storage experiment $(24 \mathrm{~h})$

\section{RESULTS AND DISCUSSION}

Beech wood and impregnated beech wood characterisation 
The carbon $(\mathrm{C})$, hydrogen $(\mathrm{H})$ and nitrogen $(\mathrm{N})$ analyses for beech wood were as follows: $49.66 \% \mathrm{C} ; 6.29 \% \mathrm{H} ;<0.10 \% \mathrm{~N}$. Accuracy is $\pm 0.30 \%$ absolute. Elemental analysis for beech wood is given in Table 2. An elemental analysis was not performed for each impregnated beech wood sample as it was assumed that each sample would have the same elemental content as untreated beech wood. All samples of beech wood were from a single batch. The potassium and phosphorus content of raw and impregnated beech wood samples are shown in Table 3.

DTG profiles for each $\mathrm{K}$ and P-impregnated beech wood sample are shown in Figure 2 and Figure 3 respectively.

Table 2. Elemental analysis of beech wood

\begin{tabular}{|c|c|}
\hline Measurement & Beech wood \\
\hline ASTM ash content (wt. $\%{ }^{\text {d.b. }}$ ) & 0.63 \\
\hline $\mathrm{C}$ (wt. \% ${ }^{\text {d.a.f }}$ ) & 49.66 \\
\hline $\mathrm{H}$ & 6.29 \\
\hline $\mathrm{N}$ & $<0.10$ \\
\hline $\mathrm{O}^{*}$ & 43.95 \\
\hline HHV (MJ kg. $\left.{ }^{-1}\right)$ & 19.81 \\
\hline LHV & 18.44 \\
\hline - dry basis & \\
\hline d.a.f. $\quad$ - dry ash free & \\
\hline * $\quad$ - by difference & \\
\hline
\end{tabular}


Table 3. Elemental analysis of impregnated beech wood-potassium and phosphorus content

\begin{tabular}{llllll}
\hline & Beech wood & $0.10 \mathrm{~K}$ & $0.50 \mathrm{~K}$ & $1.00 \mathrm{~K}$ & $2.00 \mathrm{~K}$ \\
\hline K (wt. \% $\left.{ }^{\text {d.b. }}\right)$ & 0.05 & 0.16 & 0.54 & 0.94 & 1.53 \\
\hline & & & & & \\
\hline & Beech Wood & $0.10 \mathrm{P}$ & $0.50 \mathrm{P}$ & $1.00 \mathrm{P}$ & $2.00 \mathrm{P}$ \\
\hline P (wt. \% ${ }^{\text {d.b. })}$ & 0.01 & 0.11 & 0.56 & 0.94 & 1.89 \\
\hline d.b. $\quad$ - dry basis & & & & \\
\hline
\end{tabular}

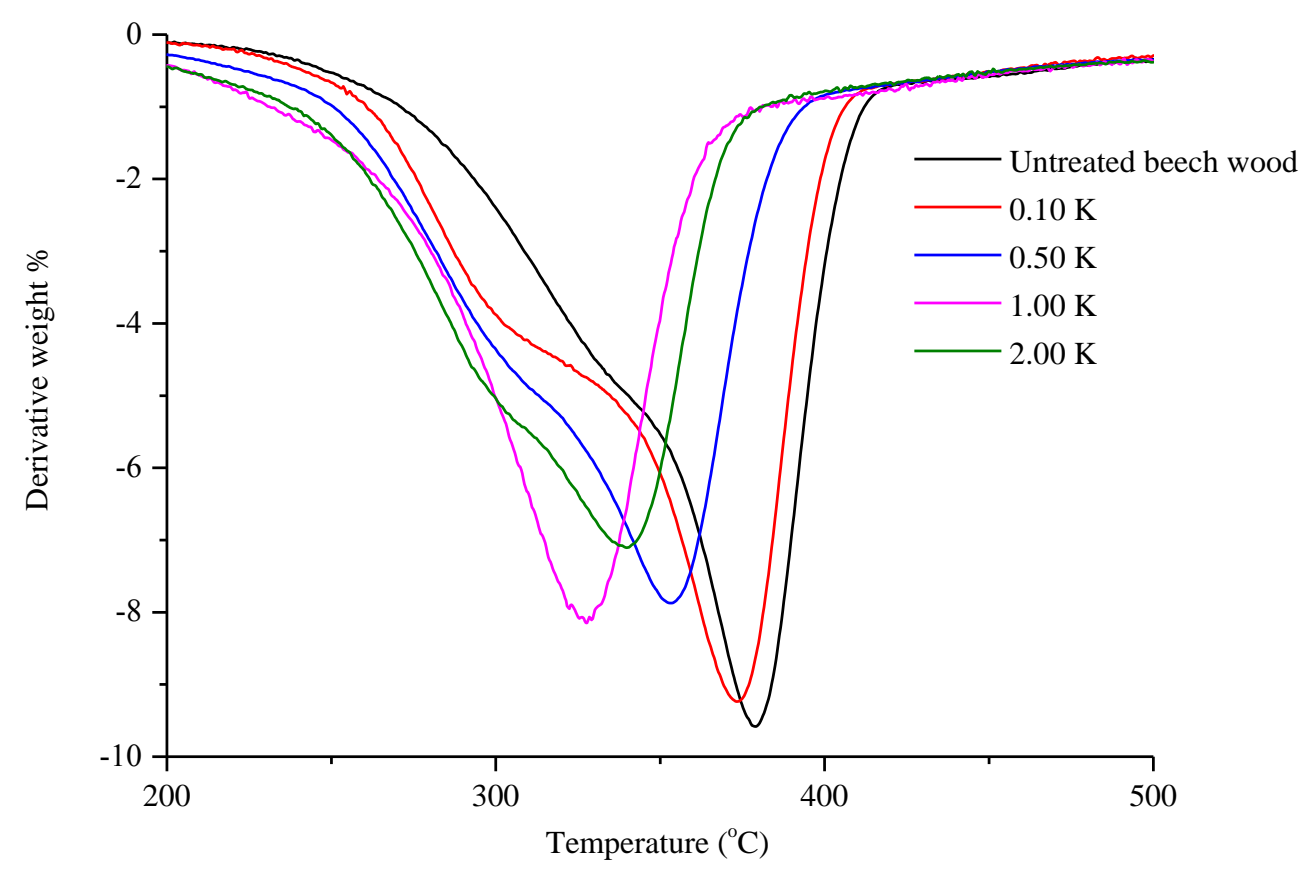

Figure 2. Pyrolysis DTG profile for K-impregnated beech wood 


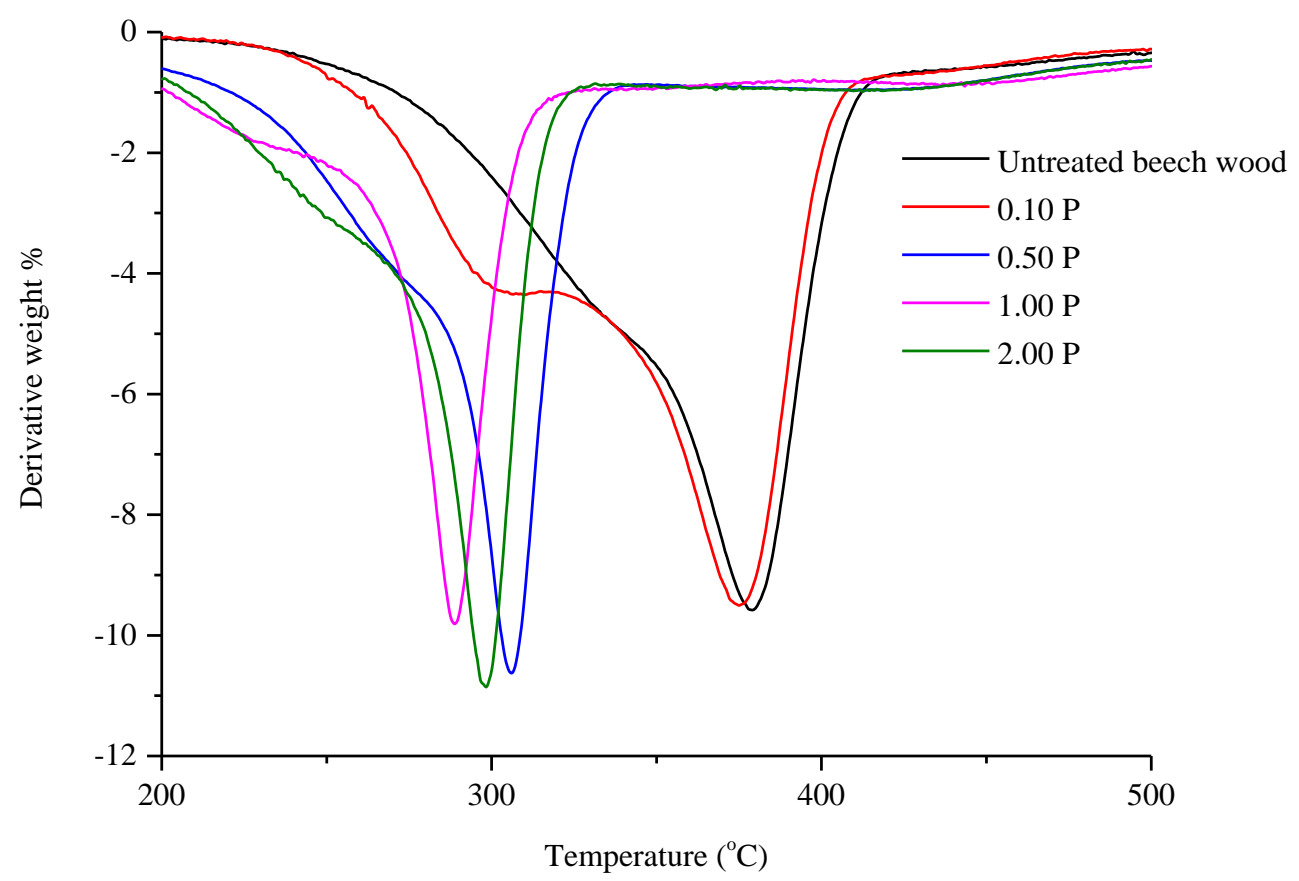

Figure 3. Pyrolysis DTG profile for P-impregnated beech wood

Pyrolytic decomposition of all impregnated samples began around $200{ }^{\circ} \mathrm{C}$. Major mass loss occurs at the temperature range between 250 and $450{ }^{\circ} \mathrm{C}$ during which volatile matter is released, with the formation of char and evolution of secondary gases.

The main temperature peaks for untreated beech wood, $0.10 \% \mathrm{~K}, 0.50 \% \mathrm{~K}, 1.00 \% \mathrm{~K}$ and $2.00 \%$ $\mathrm{K}$ are: $378^{\circ} \mathrm{C}, 375^{\circ} \mathrm{C}, 358^{\circ} \mathrm{C}, 330^{\circ} \mathrm{C}$ and $343^{\circ} \mathrm{C}$ respectively (Figure 2). The shapes of the DTG profiles are largely reflective of the cellulose, hemicellulose and lignin content. The shoulder like feature on the DTG curves can be attributed to the degradation of hemicellulose. Thermal decomposition of hemicellulose takes place at lower temperatures when compared to cellulose [33], and the thermal decomposition of lignin occurs over abroad temperature range, and partially contributes to the cellulose and hemicellulose regions [34]. The DTG profiles for K-impregnated beech wood show that as the concentration of elemental potassium increases the main peak 
temperature decreases gradually. The $0.10 \%$ potassium had little effect on the main peak temperature compared to the untreated beech wood $\left(3^{\circ} \mathrm{C}\right.$ difference); $0.50 \% \mathrm{~K}, 1.00 \% \mathrm{~K}$ and $2.00 \%$ $\mathrm{K}$ lower the temperature of the main peak even further $\left(20^{\circ} \mathrm{C}, 48^{\circ} \mathrm{C}\right.$ and $35^{\circ} \mathrm{C}$ difference respectively). The $2.00 \% \mathrm{~K}$ impregnation was expected to have the lowest main peak temperature as it had the highest potassium content. There is a reduction in main peak temperature because as the amount of potassium present in biomass increases it becomes more effective in catalysing pyrolysis [8]. Lower amounts of volatiles were observed for higher concentrations of potassium compared to beech wood identifying increased catalytic cracking. Increased potassium content had a large impact on char formation: char yields increased from $22.19 \%$ (beech wood) to $28.75 \%$ $(1.00 \mathrm{~K})$. Char yields increased due to alkali metal content (in particular potassium) which acts as a catalyst for promoting char formation [35, 36]. Ash content increases with increased concentrations of potassium (results not shown).

The main temperature peaks for untreated beech wood, $0.10 \% \mathrm{P}, 0.50 \% \mathrm{P}, 1.00 \% \mathrm{P}$ and $2.00 \%$ P are: $378^{\circ} \mathrm{C}, 377^{\circ} \mathrm{C}, 310^{\circ} \mathrm{C}, 291^{\circ} \mathrm{C}$ and $301^{\circ} \mathrm{C}$ respectively (Figure 3). The DTG profiles for Pimpregnated beech wood show that as the concentration of elemental phosphorus increases the main peak temperature decreases dramatically. The $0.10 \%$ phosphorus had little effect on the main peak temperature compared to the untreated beech wood $\left(10^{\circ} \mathrm{C}\right.$ difference $) ; 0.50 \% \mathrm{P}, 1.00 \% \mathrm{P}$ and $2.00 \% \mathrm{P}$ lower the temperature of the main peak even further $\left(68^{\circ} \mathrm{C}, 87^{\circ} \mathrm{C}\right.$ and $77^{\circ} \mathrm{C}$ difference respectively). It seems that as the concentration of phosphorus increases, the more effective it becomes at catalysing pyrolysis as shown by lowering main peak temperatures and increasing char yields. Lower amounts of volatiles were observed for higher concentrations of phosphorus compared to beech wood (results not shown). Increased phosphorus content had a large impact on char formation; char yields increased from $22.19 \%$ (untreated beech wood) to $41.30 \%$ ( $2.00 \% \mathrm{P})$. 
Phosphorus compounds are well known flame- retardants [37, 38], resulting in increased char yields. Ash content increases with increased concentrations of phosphorus (results not shown). Pyrolysis-gas chromatography-mass spectrometry (Py-GC-MS) analysis was introduced to study the generation of hydrocarbons produced during pyrolysis of raw as well as potassium and phosphorus impregnated beech wood. Chromatograms for this analysis are given in Figure 4 (AC). In general Py-GC-MS profiles for raw and potassium impregnated samples are very similar, but in case of K-impregnated and P-impregnated samples levoglucosan (RT=30.06 min.) abundance is very low. Inorganic cations can act as a cracking catalyst for almost complete decomposition of glucosidic units by a heterolytic mechanism [8]. This type of in-situ catalysis favours direct depolymerisation and fragmentation of cellulose and hemicellulose constituents, which leads to formation of low molecular weight components such as acetic acid ( $\mathrm{RT}=.3 .09 \mathrm{~min}$.), 2(5H)-furanone ( $\mathrm{RT}=4.75 \mathrm{~min}$.), furfural $(\mathrm{RT}=5.49 \mathrm{~min}$.). 3-furaldehyde ( $\mathrm{RT}=7.94 \mathrm{~min}$.) and levoglucosenone ( $\mathrm{RT}=17.02 \mathrm{~min}$.) become more dominant pyrolysis products in case of Pimpregnated beech wood, what points to different rearrangement and dehydration routes during the pyrolytic decomposition [15]. Phenol (RT=12.42 min.) and 2,6-dimethoxy-phenol (RT=15.95 min.) were not produced when phosphorus was present. 

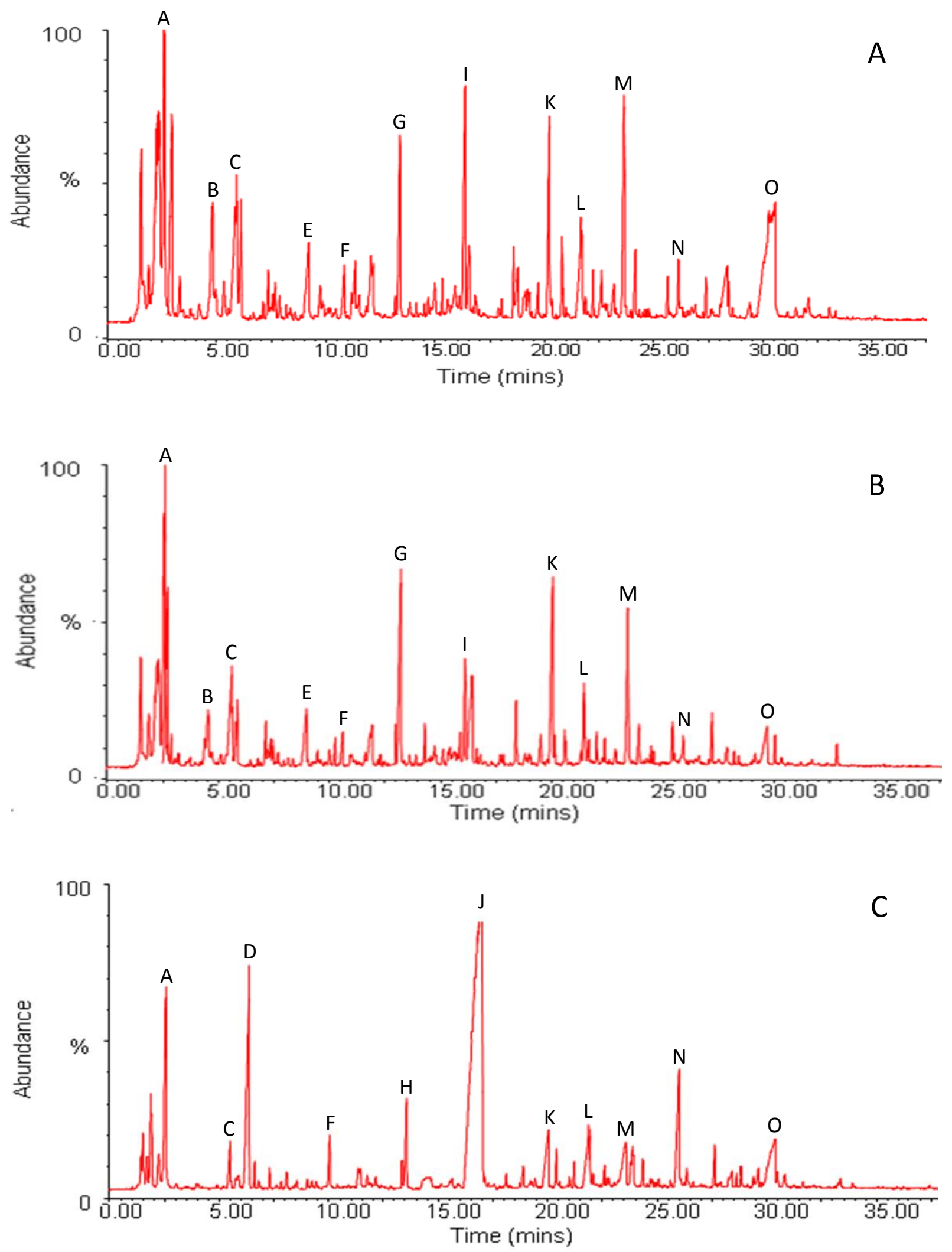
Figure 4. Py-GC-MS chromatograms for: $\mathbf{A}$ - untreated beech wood, $\mathbf{B}-1 \% \mathrm{~K}$ impregnated sample, $\mathrm{C}-1 \% \mathrm{P}$ impregnated sample

Retention times and GC-MS peak assignments: 2-butanone (2.29 min.); acetic acid (3.09 min, A); 2(5H)-furanone (4.75 min. B); furfural (5.49 min., C); 3-furaldehyde (7.94 min., D); 2-hydroxy2-cyclopenten-1-one (9.41 min.; E); 5-methyl-2-furancarboxaldehyde (10.98 min., F); phenol (12.42 min., G); 2-methoxy-phenol (13.08 min., H); 2,6-dimethoxy-phenol (15.95 min., I); Levoglucosenone (17.02 min., J); eugenol (20.99 min., K); 2-methoxy-4-(1-propenyl)-phenol (22.13 min., L); 1,2,3-trimethoxy-5-methyl-benzaldehyde (23.04 min., M); vanillin (25.83 min., $\mathrm{N})$; levoglucosan (30.06 min., O)

Fast pyrolysis experiments for potassium impregnated beech wood

The fast pyrolysis mass balances for untreated and K-impregnated beech wood are summarised in Table 4.

Table 4. K-impregnation fast pyrolysis mass balances and product properties

\begin{tabular}{|c|c|c|c|c|c|}
\hline \multicolumn{6}{|l|}{ K-impregnation } \\
\hline & $\begin{array}{l}\text { Beech } \\
\text { wood }\end{array}$ & $0.10 \mathrm{~K}$ & $0.50 \mathrm{~K}$ & $1.00 \mathrm{~K}$ & $2.00 \mathrm{~K}$ \\
\hline \multicolumn{6}{|c|}{ Yield, (wt. \% on dry feed basis) } \\
\hline Char & 13.18 & 14.80 & 18.02 & 24.62 & 28.94 \\
\hline Bio-oil & 70.69 & 58.09 & 52.12 & 40.42 & 34.84 \\
\hline Phase & Single & Single & Single & Separated & Separated \\
\hline Organics & 63.41 & 46.70 & 35.42 & 25.23 & 21.23 \\
\hline Reaction water & 7.27 & 11.40 & 16.70 & 15.20 & 13.61 \\
\hline Gas & 11.37 & 14.71 & 17.68 & 24.29 & 24.26 \\
\hline $\begin{array}{l}\text { Mass balance } \\
\text { closure }\end{array}$ & 95.23 & 87.60 & 87.83 & 89.33 & 88.04 \\
\hline
\end{tabular}




\begin{tabular}{|c|c|c|c|c|c|}
\hline \multicolumn{6}{|l|}{ Char Properties } \\
\hline Ash (wt. \% ${ }^{\text {d.b. }}$ ) & 3.58 & 5.79 & 10.53 & 19.54 & 27.91 \\
\hline $\mathrm{C}$ (wt. \% $\left.{ }^{\text {d.a.f. }}\right)$ & 75.70 & 80.85 & 84.59 & 94.47 & 92.65 \\
\hline $\mathrm{H}$ & 3.51 & 3.28 & 3.57 & 3.67 & 3.48 \\
\hline $\mathrm{N}$ & 0.37 & 0.47 & 0.11 & 0.51 & 0.55 \\
\hline $\mathrm{O}^{*}$ & 20.42 & 15.40 & 11.73 & 1.35 & 3.32 \\
\hline HHV (MJ kg. $\left.{ }^{-1}\right)$ & 30.69 & 31.37 & 33.89 & 40.00 & 38.40 \\
\hline LHV & 29.93 & 30.66 & 33.11 & 39.20 & 37.64 \\
\hline \multicolumn{6}{|l|}{ Bio-oil properties } \\
\hline 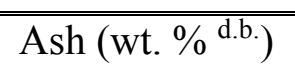 & $\mathrm{n} / \mathrm{a}$ & $\mathrm{n} / \mathrm{a}$ & $\mathrm{n} / \mathrm{a}$ & $\mathrm{n} / \mathrm{a}$ & $\mathrm{n} / \mathrm{a}$ \\
\hline $\mathrm{C}$ (wt. \% d.a.f. $)$ & 46.19 & 51.40 & 46.09 & 59.36 & 56.56 \\
\hline $\mathrm{H}$ & 7.91 & 8.26 & 7.91 & 8.79 & 7.39 \\
\hline $\mathrm{N}$ & 0.22 & 0.10 & 0.10 & 0.10 & 0.10 \\
\hline $\mathrm{O}^{*}$ & 45.68 & 40.24 & 45.90 & 31.75 & 35.95 \\
\hline$\overline{\mathrm{HHV}}\left(\mathrm{MJ} \mathrm{kg.}^{-1}\right)$ & 18.55 & 21.39 & 18.49 & 26.46 & 23.77 \\
\hline LHV & 16.83 & 19.58 & 16.76 & 24.55 & 22.16 \\
\hline$\overline{\mathrm{pH}}$ & 2.43 & 3.02 & 3.15 & 3.35 & 3.35 \\
\hline \multicolumn{6}{|l|}{ d.b. $\quad$ - dry basis } \\
\hline \multicolumn{6}{|c|}{ d.a.f. $\quad$ - dry ash free } \\
\hline - by differ & & & & & \\
\hline $\mathrm{n} / \mathrm{a} \quad$ - not analy & & & & & \\
\hline
\end{tabular}

Acceptable mass balance closures were achieved for all potassium impregnation concentrations $(>87 \%)$. Losses in the mass balance are down to bio-oil holdup in the quench column, partial 21 
dissolution of some pyrolysis products in the ISOPAR ${ }^{\mathrm{TM}}$ and undetected and unidentified permanent gases. Yields of fast pyrolysis products for different potassium impregnation concentrations are compared in Figure 5.

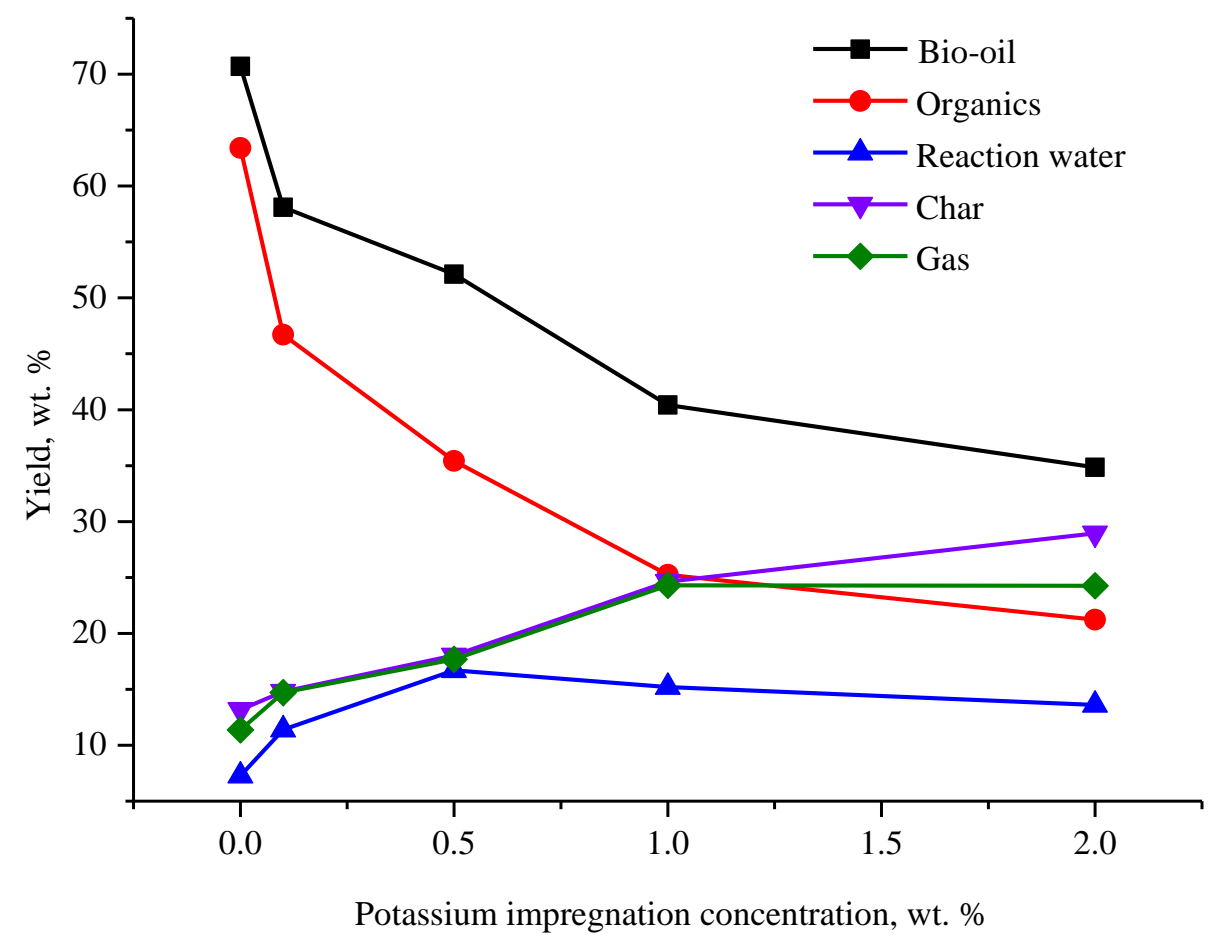

Figure 5. Yields of fast pyrolysis products for different potassium impregnation concentrations

The total bio-oil yields obtained for K-impregnated beech wood decrease as the weight per cent of potassium impregnated increases from 58.09 wt. \% (0.10\% potassium) to $34.36 \mathrm{wt} . \%$ (2.00\% potassium). As expected the organic content in bio-oil was reduced dramatically from 63.41 wt. $\%$ (untreated beech wood) to $21.23 \mathrm{wt} . \%(2.00 \%$ potassium). Potassium increased char and water production at the expense of the liquid phase organic products [39]. Increased potassium content resulted in the reaction water yield increasing from 7.27 wt. \% (untreated beech wood) up to 15.2 
wt. $\%(1.00 \%$ potassium $)$, due to the increased amount of cracking of organics to water and carbon dioxide. Char yields increase with increased potassium concentrations from 14.8 wt. \% (0.10\% potassium) to 28.94 wt. $\%$ (2.00\% potassium); this would suggest that char yields would continue to rise until levelling at a certain concentration of K-impregnation. The changes in liquid and char yields can be attributed to the increased potassium content which acts as a catalyst for promoting char formation [35]. Higher than expected char ash contents were achieved which was due to silica sand becoming entrained in the fluidisation and product gases from the reactor and being collected in the char cyclone. The presence of silica in the char will greatly increase the ash content of the char product. Gas yields increase also with increased potassium concentration from 14.71 wt. \% $(0.10 \%$ potassium $)$ to $24.26 \mathrm{wt} . \%(2.00 \%$ potassium $)$, but when the concentration of potassium reached $1.00 \%$ the gas yield levelled out at $24.26-24.29$ wt. $\%(2.00 \%$ potassium and $1.00 \%$ potassium respectively).

A main factor in bio-oil quality is whether the bio-oil is single phase and phase separation is probably the most important characteristic of bio-oil as phase separation cannot be readily reversed. At some point between $0.50 \%$ and $1.00 \% \mathrm{~K}$-impregnation the bio-oil produced becomes phase separated (due to higher total water content). Generally, as water content increases, bio-oil is expected to phase separate; an upper phase which is a water-rich phase and a lower phase which is viscous with high tar content [40]. This identifies that potassium concentrations have to be kept below a certain concentration so that the quality of bio-oil can be maintained. Potassium has a chemical effect on the primary decomposition paths of cellulose, hemicellulose and lignin and increases the activity of secondary reactions. The addition of potassium, even in low amounts, causes major changes on the yields of char, water and gas formation all at the expense of organic yields. Alkali metals favour dehydration, demethoxylation, decarboxylation, demethylation and 
char formation $[41,42]$ in the primary decomposition of lignin. While processing K-impregnated beech wood no processing problems occurred.

Char higher heating values were similar for untreated beech wood, 0.10 and $0.50 \% \mathrm{~K}$ (30.69, 31.37 and $33.89 \mathrm{MJ} \mathrm{kg}^{-1}$ respectively), but when the concentration of potassium was increased to 1.00 and $2.00 \%$ the heating value increased to 40.00 and $38.40 \mathrm{MJ} \mathrm{kg.}{ }^{-1}$ respectively. Heating values for bio-oil produced from K-impregnated beech wood showed no specific trend, with $1.00 \%$ $\mathrm{K}$ having the highest value $\left(26.46 \mathrm{MJ} \mathrm{kg}^{-1}\right)$ and $0.50 \% \mathrm{~K}$ having the lowest value $(18.49 \mathrm{MJ} \mathrm{kg}$.' $\left.{ }^{1}\right)$.

Fast pyrolysis experiments for phosphorus impregnated beech wood

The fast pyrolysis mass balances for untreated and P-impregnated beech wood are summarised in Table 5. Acceptable mass balance closures were achieved for all phosphorus impregnation concentrations $(>88 \%)$. The total bio-oil yields obtained for P-impregnated beech wood decrease as the weight per cent of phosphorus impregnated increases from $66.62 \mathrm{wt} . \%$ ( $0.10 \%$ phosphorus) to 52.38 wt. $\%$ ( $2.00 \%$ phosphorus). The organic content in bio-oil was reduced from 63.41 wt. $\%$ (untreated beech wood) to between 30.74 and 36.09 wt. \% (0.50\% phosphorus and $2.00 \%$ phosphorus respectively). Reaction water yields increased from $7.27 \mathrm{wt}$ \% (untreated beech wood) up to 19.47 wt. $\%$ ( $0.50 \%$ phosphorus) indicating more dehydration reactions taking place during fast pyrolysis. The primary breakdown of the cellulose structure due to pyrolysis at low temperatures results in the main products being carbon dioxide, carbon monoxide, water and char [43], phosphorus reduces the temperature of fast pyrolysis (Figure 3) therefore favouring the dehydration pathway (increasing reaction water yields). Yields of fast pyrolysis products for different phosphorus impregnation concentrations are compared in Figure 6.

Table 5. P-impregnation fast pyrolysis mass balances and product properties 
P-impregnation

\begin{tabular}{lllll}
\hline Beech & $0.10 \mathrm{P}$ & $0.50 \mathrm{P}$ & $1.00 \mathrm{P}$ & $2.00 \mathrm{P}$ \\
wood & & & & \\
\end{tabular}

Yield, (wt. \% on dry feed basis)

\begin{tabular}{lccccc}
\hline Char & 13.18 & 9.41 & 25.49 & 30.21 & 26.00 \\
\hline Bio-oil & 70.69 & 66.62 & 50.21 & 52.84 & 52.38 \\
Phase & Single & Single & Single & Single & Single \\
Organics & 63.41 & 55.77 & 30.74 & 34.69 & 36.09 \\
Reaction water & 7.27 & 10.85 & 19.47 & 18.15 & 16.29 \\
\hline Gas & 11.37 & 15.79 & 13.26 & 15.59 & 11.25 \\
\hline Mass & balance & & & & \\
closure & 95.23 & 91.82 & 88.96 & 98.65 & 89.64 \\
\hline \hline
\end{tabular}

Char Properties

\begin{tabular}{llllll}
\hline \hline Ash (wt. \% ${ }^{\text {d.b. }}$ ) & 3.58 & 8.05 & 18.72 & $\mathrm{n} / \mathrm{d}$ & $\mathrm{n} / \mathrm{d}$ \\
\hline $\mathrm{C}$ (wt. \% ${ }^{\text {d.a.f. }}$ ) & 75.70 & 82.37 & 88.28 & $76.15^{\#}$ & $78.72^{\#}$ \\
$\mathrm{H}$ & 3.51 & 3.40 & 3.25 & $3.12^{\#}$ & $3.00^{\#}$ \\
$\mathrm{~N}$ & 0.37 & 0.54 & 0.43 & $0.41^{\#}$ & $0.45^{\#}$ \\
$\mathrm{O}^{*}$ & 20.42 & 13.69 & 8.04 & $20.32^{\#}$ & $17.83^{\#}$ \\
\hline HHV (MJ kg. & & & & 29.80 \\
LHV & 30.69 & 28.60 & 26.09 & 28.78 & 29.14 \\
\hline \hline Bio-oil properties & 29.93 & 27.92 & 25.51 & 28.10 & \\
\hline \hline Ash (wt. \% ${ }^{\text {d.b. }}$ & & & & \\
\hline
\end{tabular}




\begin{tabular}{|c|c|c|c|c|c|c|}
\hline \multicolumn{2}{|c|}{ C (wt. \% d.a.f. $^{\text {f }}$} & 46.19 & 50.82 & 47.04 & 52.26 & 47.35 \\
\hline \multicolumn{2}{|l|}{$\mathrm{H}$} & 7.91 & 7.22 & 6.80 & 9.39 & 7.62 \\
\hline \multicolumn{2}{|l|}{$\mathrm{N}$} & 0.22 & 0.36 & 0.10 & 0.24 & 0.10 \\
\hline \multicolumn{2}{|l|}{$\mathrm{O}^{*}$} & 45.68 & 41.60 & 46.06 & 38.25 & 44.93 \\
\hline \multicolumn{2}{|c|}{$\mathrm{HHV}\left(\mathrm{MJ} \mathrm{kg.}^{-1}\right)$} & 18.55 & 20.71 & 18.77 & 22.39 & 19.07 \\
\hline \multicolumn{2}{|c|}{ LHV } & 16.83 & 19.14 & 17.28 & 20.34 & 17.40 \\
\hline \multicolumn{2}{|l|}{$\mathrm{pH}$} & 2.43 & 3.11 & 3.17 & 3.27 & 3.51 \\
\hline d.b. & - dry basis & & & & & \\
\hline d.a.f. & - dry ash free & & & & & \\
\hline$*$ & - by difference & & & & & \\
\hline $\mathrm{n} / \mathrm{a}$ & - not analysed & & & & & \\
\hline $\mathrm{n} / \mathrm{d}$ & - not determined & & & & & \\
\hline$\#$ & - CHN results on & dry basis & & & & \\
\hline
\end{tabular}




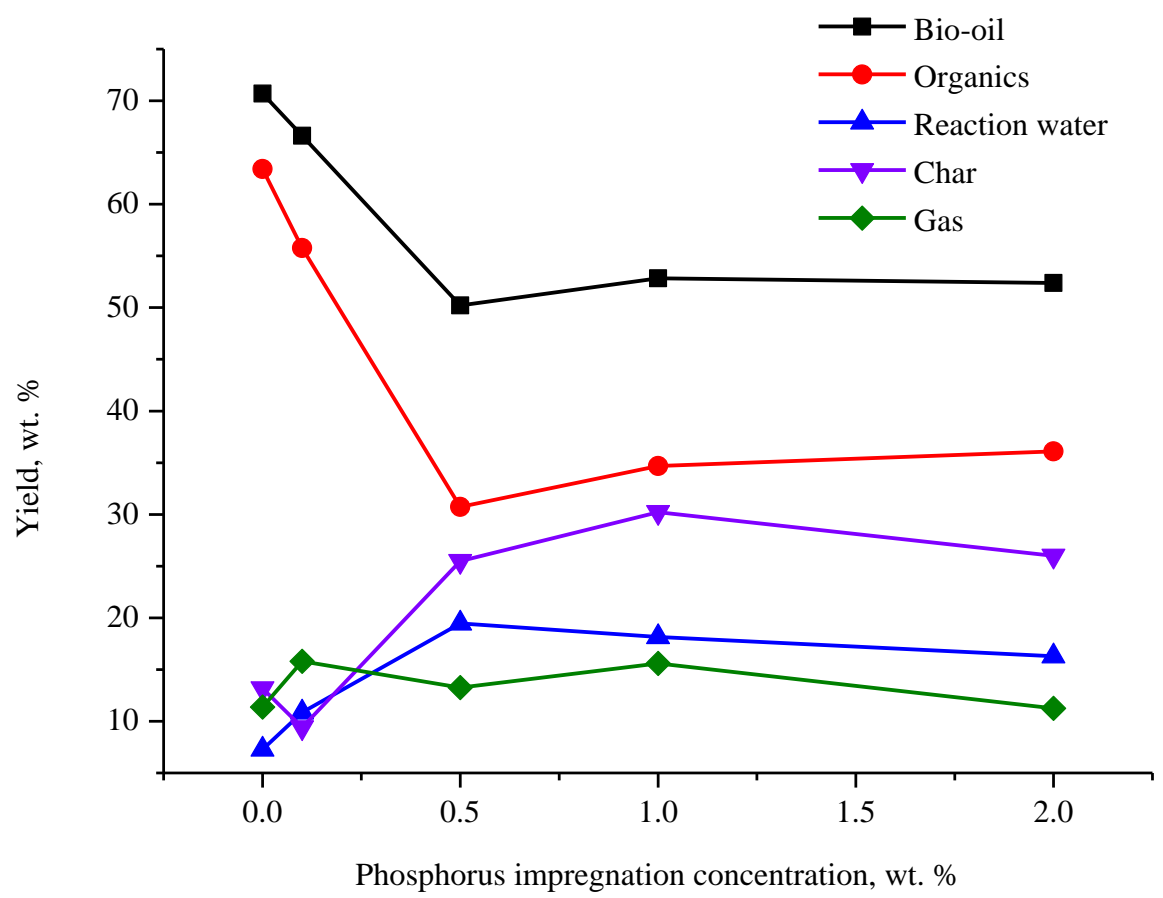

Figure 6. Yields of fast pyrolysis products for different phosphorus impregnation concentrations

Char yields increased with increased phosphorus concentrations from 9.41 wt. \% $(0.10 \%$ phosphorus) to between 25.49 and 30.21 wt. \% ( $0.50 \%$ phosphorus and $1.00 \%$ phosphorus respectively). The increase in char yields is due to acid catalysed condensation reactions [44]; higher phosphorous content increases the char formation due to increased catalysis of condensation reactions. It is also well known that phosphorus compounds are flame-retardants [37, 38], resulting in increased char yields. Increased amounts of phosphorus above $0.50 \%$ do not seem to greatly affect char yield. Higher than expected char ash contents were achieved, which, as previously explained, are due to silica sand becoming entrained in the fluidisation and product gases from the reactor and being collected in the char cyclone. All P-impregnated beech wood bio-oil samples were single phase. 
Char higher heating values could not be compared as the ash could not be determined for phosphorus concentrations above $0.50 \%$ (Table 5), due to phosphorus forming a flame retardant layer which meant that the carbon beneath was not combusted. The CHN results are on a dry basis for 1.00 and $2.00 \%$ phosphorus and on a dry ash free basis for 0.10 and $0.50 \%$ phosphorus. Char higher heating values decreased as the concentration of phosphorus increased from 30.69 to 26.09 MJ kg. ${ }^{-1}$ (untreated beech wood and $0.50 \%$ P respectively). Heating values for bio-oil produced from P-impregnated beech wood showed no specific trend, with $1.00 \% \mathrm{P}$ having the highest value (22.39 $\left.\mathrm{MJ} \mathrm{kg.}^{-1}\right)$ and $0.50 \% \mathrm{P}$ having the lowest value $\left(18.77 \mathrm{MJ} \mathrm{kg.}{ }^{-1}\right)$.

While processing P-impregnated beech wood it was noticed that with increased phosphorus concentrations the processing became more problematic due to problems with fluidisation resulting in bed temperatures dropping resulting in a large temperature difference between the middle and bottom of the reactor. When the bed material ( $1 \mathrm{~kg}$ sieved quartz sand) was removed from the reactor it was found to have agglomerated into large clumps due to char formation within the reactor (Figure 7), affecting the fluidisation and heat transfer. By regularly increasing and decreasing the flow rate of preheated fluidising nitrogen, the bed temperature difference was reduced by breaking up the agglomerated char and sand. Figure 7 shows the agglomerated char and sand from the reactor due to increased concentrations of phosphorus. 


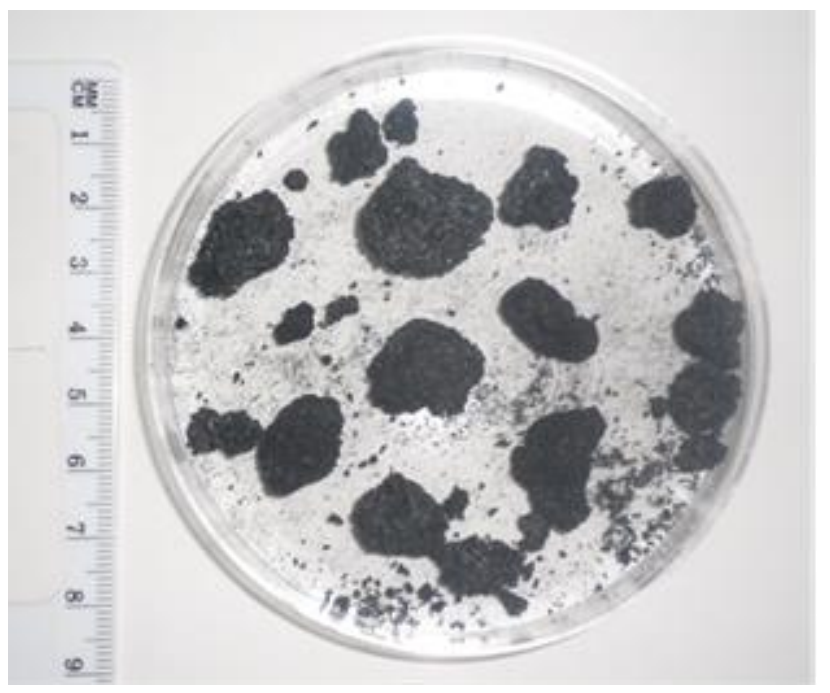

Figure 7. Agglomerated char and sand from reactor

When concentrations of phosphorus are at $0.50 \%$ or above, the yields of bio-oil, char and gases stay within a similar range (+/- 5 wt. \%) suggesting that increased concentration of phosphorus (above $0.50 \%$ ) has minimal effect on fast pyrolysis product yields. But concentrations of phosphorus at $0.50 \%$ and above lead to the processing problems described above due to an increased rate of sand/char agglomeration within the reactor.

GC-MS characterisation of pyrolysis liquids (bio-oils)

Bio-oil quality and stability

The bio-oil stability experiments for untreated, K-impregnated and P-impregnated beech wood are summarised in Table 6 and Table 7. Figure 8 and Figure 9 compare viscosity and water content stability indexes. 
Table 6. Results for the stability of bio-oils derived from K-impregnated beech wood

\begin{tabular}{|c|c|c|c|c|c|c|c|c|c|c|}
\hline Analysis & \multicolumn{10}{|c|}{ Potassium impregnation } \\
\hline Viscosity (cP) & 58.0 & 75.06 & 38.50 & 82.00 & 14.80 & 29.76 & 45.00 & 101.00 & 47.50 & 127.25 \\
\hline Water content increase $(\%)$ & 18.20 & 19.25 & 13.69 & 15.55 & 22.18 & 26.09 & 31.00 & 37.54 & 32.36 & 39.54 \\
\hline Stability index based on water & 1.06 & & 1.14 & & 1.18 & & 1.21 & & 1.22 & \\
\hline
\end{tabular}


Table 7. Results for the stability of bio-oils derived from P-impregnated beech wood

\begin{tabular}{|c|c|c|c|c|c|c|c|c|c|c|}
\hline \multirow[t]{2}{*}{ Analysis } & \multicolumn{10}{|c|}{ Phosphorus impregnation } \\
\hline & \multicolumn{2}{|c|}{ Beech wood } & \multicolumn{2}{|l|}{$0.10 \mathrm{P}$} & \multicolumn{2}{|l|}{$0.50 \mathrm{P}$} & \multicolumn{2}{|l|}{$1.00 \mathrm{P}$} & \multicolumn{2}{|l|}{$2.00 \mathrm{P}$} \\
\hline Viscosity (cP) & 58.0 & 75.06 & 82.50 & 145.36 & 100.80 & 198.30 & 145.00 & 280.00 & 12.90 & 25.60 \\
\hline Water content increase $(\%)$ & 18.20 & 19.25 & 9.23 & 10.11 & 14.95 & 16.62 & 17.16 & 19.02 & 16.31 & 17.67 \\
\hline Stability index based on water & 1.06 & & 1.10 & & 1.11 & & 1.11 & & 1.08 & \\
\hline
\end{tabular}




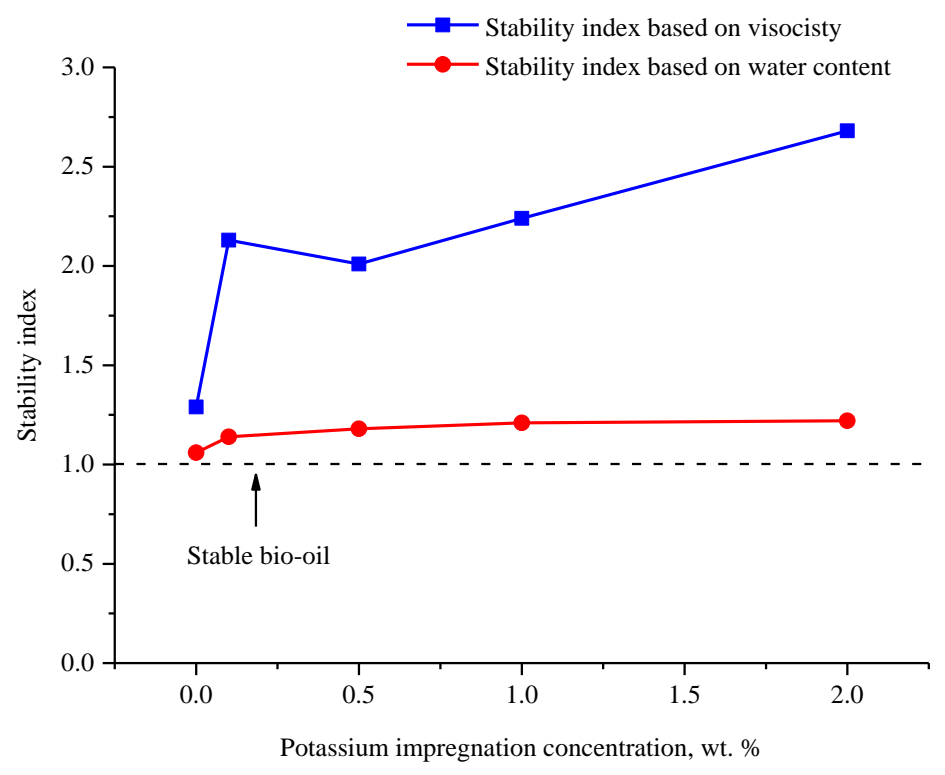

Figure 8. Comparison of viscosity and water content stability indexes for different potassium impregnation concentrations

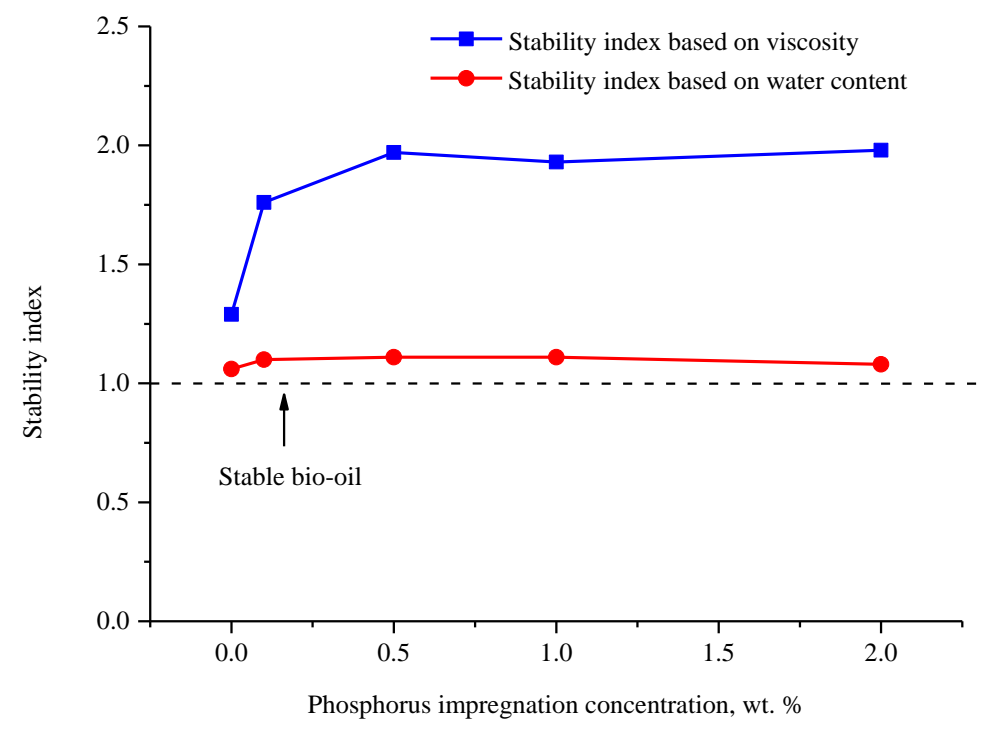

Figure 9. Comparison of viscosity and water content stability indexes for different phosphorus impregnation concentrations 
An increase in viscosity for all impregnated samples was observed when the bio-oil samples were placed in the accelerated storage experiment. The viscosity index shows that K-impregnated beech wood samples produce the most unstable bio-oils $(2.13$ to 2.68$)$, compared to the Pimpregnated beech wood bio-oils (1.76 to 1.98). The increase in viscosity index for the potassium samples suggests that increased potassium concentrations would result in the index continuing to rise. If potassium concentrations increased this would result in higher concentrations being entrained in char therefore having a greater effect on bio-oil stability. Presence of char in bio-oil seems to catalyse reactions leading to viscosity of bio-oil increasing [45]. The viscosity index for the phosphorus samples begins to settle between 1.93 and 1.98 , for $1.00 \%$ phosphorus and $2.00 \%$ phosphorus respectively.

The water content index shows a similar trend as the viscosity index for K-impregnated beech wood bio-oil samples as the index increases from $1.14(0.10 \% \mathrm{~K})$ to $1.22(2.00 \% \mathrm{~K})$. Etherification and esterification occurring between hydroxyl, carbonyl and carboxyl group components results in water being a by-product [3], as seen by the increase in water content index. P-impregnated beech wood bio-oil samples have similar water content indexes (1.08-1.11), as these indexes are similar to the untreated beech wood water content index (1.06) it suggests that phosphorus has little or no effect on the water content of the bio-oil during storage. It has been shown [19] that water content indexes do not vary much as the water release during aging is small and is over compensated by the average molecular weight increase of the bio-oil. Overall P-impregnated beech wood bio-oil samples are more stable in both viscosity and water content indexes compared to Kimpregnated beech wood bio-oil samples. 


\section{CONCLUSIONS}

Both potassium and phosphorus had negative effects on fast pyrolysis product yields and bio-oil stability. This was identified by reduced yields of bio-oil and increased char and gas yields. Potassium impregnation had a greater effect on fast pyrolysis products yields compared to phosphorus impregnation, identified by minimum yields of bio-oil (34.84 wt. \%) as well as maximum yields of non-condensable gases (24.26 wt. \%). Both potassium and phosphorus had similar maximum yields of char (28.94 and $30.21 \mathrm{wt} \%$ respectively). These results highlight that potassium and phosphorous found naturally within biomass promote the formation of char and gas at the expense of pyrolysis bio-oil.

Bio-oil stability was decreased by all impregnations. $2.00 \%$ potassium impregnated beech wood bio-oil samples are less stable in both viscosity and water content indexes (2.68 and 1.22 respectively) compared to other impregnations. Viscosity and water content indexes increased as concentrations of potassium increased. Phosphorus impregnated beech wood samples experienced increased viscosity indexes but water content indexes were similar for all impregnation concentrations. This identifies that potassium has a greater effect on further catalytic cracking or ageing reactions during storage compared to phosphorus. 


\section{AUTHOR INFORMATION}

\section{Corresponding Author}

* Telephone: +44 121 2043417. E-mail: d.j.nowakowski@aston.ac.uk

\section{Author Contributions}

The manuscript was written through contributions of all authors. All authors have given approval to the final version of the manuscript. $\$$ These authors contributed equally.

\section{ACKNOWLEDGMENT}

The authors are grateful for the financial support from SUPERGEN Bioenergy II Consortium under the Engineering and Physical Sciences Research Council, UK (EPSRC) grant no. EP/E039995/1: SUPERGEN Biomass Biofuels and Energy Crops II Core.

\section{REFERENCES}

1. Bridgwater, A.V., Review of fast pyrolysis of biomass and product upgrading. Biomass and Bioenergy, 2012, 38, 68-94.

2. Philpot, C.W., Influence of Mineral Content on the Pyrolysis of Plant Materials. Forest Science, 1970, 16, 461-471.

3. Czernik, S., D.K. Johnson, and S. Black, Stability of wood fast pyrolysis oil. Biomass and Bioenergy, 1994, 7(1-6), 187-192. 
4. Sekiguchi, Y. and F. Shafizadeh, The effect of inorganic additives on the formation, composition, and combustion of cellulosic char. Journal of Applied Polymer Science, 1984, 29(4), 1267-1286.

5. Teng, H. and Y.-C. Wei, Thermogravimetric Studies on the Kinetics of Rice Hull Pyrolysis and the Influence of Water Treatment. Industrial \& Engineering Chemistry Research, 1998, 37(10), 3806-3811.

6. Varhegyi, G., et al., Thermogravimetric-mass spectrometric characterization of the thermal decomposition of sunflower stem. Energy \& Fuels, 1989, 3(6), 755-760.

7. Hodgson, E.M., et al., Miscanthus as a feedstock for fast-pyrolysis: Does agronomic treatment affect quality? Bioresource Technology, 2010, 101(15), 6185-6191.

8. Nowakowski, D.J., et al., Potassium catalysis in the pyrolysis behaviour of short rotation willow coppice. Fuel, 2007, 86(15), 2389-2402.

9. Evans, R.J. and T.A. Milne, Molecular characterization of the pyrolysis of biomass. Energy \& Fuels, 1987, 1(2), 123-137.

10. Nik-Azar, M., et al., Mineral matter effects in rapid pyrolysis of beech wood. Fuel Processing Technology, 1997. 51(1-2), 7-17.

11. Müller-Hagedorn, M., et al., A comparative kinetic study on the pyrolysis of three different wood species. Journal of Analytical and Applied Pyrolysis, 2003, 68-69, 231-249.

12. Diebold, J.P. and S. Czernik, Additives To Lower and Stabilize the Viscosity of Pyrolysis Oils during Storage. Energy \& Fuels, 1997, 11(5), 1081-1091.

13. Oasmaa, A., et al., Fast Pyrolysis of Forestry Residue and Pine. 4. Improvement of the Product Quality by Solvent Addition. Energy \& Fuels, 2004, 18(5), 1578-1583. 
14. Mohan, D., C.U. Pittman, and P.H. Steele, Pyrolysis of Wood/Biomass for Bio-oil: A Critical Review. Energy \& Fuels, 2006, 20(3), 848-889.

15. Nowakowski, D. and J. Jones, Uncatalysed and potassium-catalysed pyrolysis of the cellwall constituents of biomass and their model compounds. Journal of Analytical and Applied Pyrolysis, 2008, 83(1), 12-25.

16. Ebringerova, A., Z. Hromadkova, and T. Heinze, Hemicellulose. Polysaccharides I, 2005, $1-67$.

17. He, R., et al., Influence of pyrolysis condition on switchgrass bio-oil yield and physicochemical properties. Bioresource Technology, 2009, 100(21), 5305-5311.

18. Diebold, J.P., I. Thermalchemie, and N.R.E. Laboratory, A Review of the Chemical and Physical Mechanisms of the Storage Stability of Fast Pyrolysis Bio-oils2000: National Renewable Energy Laboratory.

19. Oasmaa, A. and S. Czernik, Fuel Oil Quality of Biomass Pyrolysis OilsState of the Art for the End Users. Energy \& Fuels, 1999, 13(4), 914-921.

20. Yu, F., et al., Physical and chemical properties of bio-oils from microwave pyrolysis of corn stover, in Applied Biochemistry and Biotecnology, 2007, Springer, 957-970.

21. Lu, Q., X.-1. Yang, and X.-f. Zhu, Analysis on chemical and physical properties of bio-oil pyrolyzed from rice husk. Journal of Analytical and Applied Pyrolysis, 2008, 82(2), 191-198.

22. Sipilä, K., et al., Characterization of biomass-based flash pyrolysis oils. Biomass and Bioenergy, 1998, 14(2), 103-113.

23. Elliott, D.C., et al., Results of the IEA Round Robin on Viscosity and Aging of Fast Pyrolysis Bio-oils: Long-Term Tests and Repeatability. Energy \& Fuels, 2012, 26(12), 7362-7366. 
24. Standard test method for ash in biomass, 2007, ASTM International: West Conshohocken, PA.

25. Friedl, A., et al., Prediction of heating values of biomass fuel from elemental composition. Analytica Chimica Acta, 2005, 544(1-2), 191-198.

26. Channiwala, S.A. and P.P. Parikh, A unified correlation for estimating HHV of solid, liquid and gaseous fuels. Fuel, 2002. 81(8), 1051-1063.

27. International standard test method for compositional analysis by thermogravimetry, 2003, ASTM International: West Conshohocken, PA.

28. Faix, O., D. Meier, and I. Fortmann, Thermal degradation products of wood. Holz als Rohund Werkstoff, 1990, 48(7-8), 281-285.

29. Faix, O., et al., Thermal degradation products of wood. Holz als Roh- und Werkstoff, 1991, 49(5), 213-219.

30. Banks, S.W., D.J. Nowakowski, and A.V. Bridgwater, Fast pyrolysis processing of surfactant washed Miscanthus. Fuel Processing Technology, 2014, 128, 94-103.

31. Banks, S., Ash control methods to limit biomass inorganic content and its effect on fast pyrolysis bio-oil stability, 2014, Aston University.

32. Chiaramonti, D., A. Oasmaa, and Y. Solantausta, Power generation using fast pyrolysis liquids from biomass. Renewable and Sustainable Energy Reviews, 2007, 11(6), 1056-1086.

33. Varhegyi, G., et al., Kinetics of the thermal decomposition of cellulose, hemicellulose, and sugarcane bagasse. Energy \& Fuels, 1989. 3(3): p. 329-335.

34. Yang, H., et al., Characteristics of hemicellulose, cellulose and lignin pyrolysis. Fuel, 2007. 86(12): p. 1781-1788. 
35. Raveendran, K., A. Ganesh, and K.C. Khilar, Influence of mineral matter on biomass pyrolysis characteristics. Fuel, 1995, 74(12), 1812-1822.

36. Gray, M.R., W.H. Corcoran, and G.R. Gavalas, Pyrolysis of a wood-derived material. Effects of moisture and ash content. Industrial \& Engineering Chemistry Process Design and Development, 1985, 24(3), 646-651.

37. Gaan, S. and G. Sun, Effect of phosphorus and nitrogen on flame retardant cellulose: A study of phosphorus compounds. Journal of Analytical and Applied Pyrolysis, 2007, 78(2), 371377.

38. Stevens, R., et al., The structure-activity relationship of fire retardant phosphorus compounds in wood. Polymer Degradation and Stability, 2006, 91(4), 832-841.

39. Di Blasi, C., A. Galgano, and C. Branca, Effects of Potassium Hydroxide Impregnation on Wood Pyrolysis. Energy \& Fuels, 2009, 23, 1045-1054.

40. Jung, S.-H., B.-S. Kang, and J.-S. Kim, Production of bio-oil from rice straw and bamboo sawdust under various reaction conditions in a fast pyrolysis plant equipped with a fluidized bed and a char separation system. Journal of Analytical and Applied Pyrolysis, 2008, 82(2), 240-247.

41. Jakab, E., O. Faix, and F. Till, Thermal decomposition of milled wood lignins studied by thermogravimetry/mass spectrometry. Journal of Analytical and Applied Pyrolysis, 1997, 40-41, 171-186.

42. Kleen, M. and G. Gellerstedt, Influence of inorganic species on the formation of polysaccharide and lignin degradation products in the analytical pyrolysis of pulps. Journal of Analytical and Applied Pyrolysis, 1995, 35(1), 15-41.

43. Granzow, A., Flame retardation by phosphorus compounds. Accounts of Chemical Research, 1978, 11(5), 177-183. 
44. Dobele, G., et al., Volatile products of catalytic flash pyrolysis of celluloses. Journal of Analytical and Applied Pyrolysis, 2001, 58-59, 453-463.

45. Agblevor, F.A. and S. Besler, Inorganic Compounds in Biomass Feedstocks. 1. Effect on the Quality of Fast Pyrolysis Oils. Energy \& Fuels, 1996, 10(2), 293-298.

\section{LIST OF FIGURE CAPTIONS}

Figure 1. $1 \mathrm{~kg} \mathrm{h.-1} \mathrm{fast} \mathrm{pyrolysis} \mathrm{rig} \mathrm{set-up}$

Figure 2. Pyrolysis DTG profile for K-impregnated beech wood

Figure 3. Pyrolysis DTG profile for P-impregnated beech wood

Figure 4. Py-GC-MS chromatograms for: $\mathbf{A}$ - untreated beech wood, $\mathbf{B}-1 \% \mathrm{~K}$ impregnated sample, $\mathrm{C}-1 \% \mathrm{P}$ impregnated sample

Figure 5. Yields of fast pyrolysis products for different potassium impregnation concentrations

Figure 6. Yields of fast pyrolysis products for different phosphorus impregnation concentrations

Figure 7. Agglomerated char and sand from reactor

Figure 8. Comparison of viscosity and water content stability indexes for different potassium impregnation concentrations

Figure 9. Comparison of viscosity and water content stability indexes for different phosphorus impregnation concentrations

\section{LIST OF TABLE CAPTIONS}

Table 1. Fast pyrolysis processing parameters

Table 2. Elemental analysis of beech wood

Table 3. Elemental analysis of impregnated beech wood- potassium and phosphorus content 
Table 4. K-impregnation fast pyrolysis mass balances and product properties Table 5. P-impregnation fast pyrolysis mass balances and product properties

Table 6. Results for the stability of bio-oils derived from K-impregnated beech wood Table 7. Results for the stability of bio-oils derived from P-impregnated beech wood 